\title{
Ranking Mediterranean-type shrubs and trees by their allelopathic activity is not independent of how extract concentration is expressed
}

\author{
I. P. Pereira ${ }^{1,2, \dagger}$, L. S. Dias ${ }^{2, *}$ and A. S. Dias ${ }^{2}$ \\ ${ }^{1}$ Instituto de Ciências Agrárias e Ambientais Mediterrânicas, Universidade de Évora, Évora, Portugal \\ ${ }^{2}$ Departamento de Biologia, Universidade de Évora, Évora, Portugal
}

Water extracts from 19 Mediterranean-type shrubs and trees were screened for phytoactivity on germination of lettuce. The existing model for the effects of $\mathbf{p H}$ and osmotic pressure on germination requires refitting. Extract concentrations were expressed as plant fresh weight, plant dry weight and extract dry weight, and final ranking of the six phytoactive species was found to strongly depend on the way the concentrations are expressed. This methodological issue requires consideration when designing allelopathic bioassays. Extract dry weight is conceptually the most adequate way to express concentration and should be used, despite the increase in time and labour it requires.

Keywords: Allelopathy, extract concentration, germination, osmotic pressure.

Allelopathy refers to all types of effect in one plant produced by chemical compounds synthesized by another or the same plant, the term having been coined in the late 1930s (ref. 1). Research on allelopathy relies heavily on bioassays in which effects of extracts of plant parts on germination or growth are investigated. A number of methodological requirements of bioassays have been examined, including the dependency of functional availability of phytochemicals on seed density ${ }^{2,3}$, the relevance of seed morphology ${ }^{4}$, selection of target species or culti$\operatorname{vars}^{5}$, types of solvent used for phytochemicals extraction $^{6}$, and combined effects of $\mathrm{pH}$ and osmotic pressure of solutions ${ }^{7}$.

However, except when compounds are tested individually, single dose or dose-response designs have to deal with the concentration of tested extracts. This also applies to the study and modelling of the putative hormetic, dual actions (stimulation and inhibition) of mixtures of allelochemicals ${ }^{8}$ or the study of density-dependent phytotoxicity ${ }^{2,9}$.

Therefore questions inevitably arise on how to express concentration, i.e. in relation to the fresh weight of plant

\footnotetext{
*For correspondence. (e-mail: lsdias@uevora.pt)

†Deceased 12 May 2016
}

parts extracted, to their dry weight or to the dry weight of the compounds extracted. To answer these questions we set out to investigate the effects, corrected for $\mathrm{pH}$ and osmotic pressure, of a series of concentrations of water extracts of intact above-ground vegetative parts of Mediterranean-type shrubs or trees. Since the range of $\mathrm{pH}$ and osmotic pressure of extracts lay outside the range to which the equations were fitted ${ }^{7}$, the original model was extended and a new equation had to be fitted.

\section{Materials and methods}

\section{Plant materials and extraction}

Nineteen Mediterranean-type species, mostly noncultivated aromatic shrubs, from ten different families (Supplementary Table 1), were harvested in mid-winter before flowering, near Valverde, Évora, southern Portugal. Seeds of lettuce (Lactuca sativa L. cv. 'Rainha de Maio'; Asteraceae) were used in the bioassays.

Vegetative shoots were collected and transported in refrigerated plastic bags to the laboratory, where $30 \mathrm{~g}$ of intact leaves (because of the spiny nature of leaves or their replacement by spines complete shoot tops were used in Calicotome villosa and Ulex parviflorus) weighed to the nearest milligram were soaked in distilled water and extracted for $40 \mathrm{~h}$ at $30^{\circ} \mathrm{C}$ and constant darkness. For Eucalyptus globulus, because of its marked leaf heteroblasty young and mature leaves were separately extracted.

Extracts were filtered through Whatman No. 1 filter paper and adjusted to the concentration of $100 \mathrm{mg} \mathrm{ml}^{-1}$ (plant fresh weight volume ${ }^{-1}$, PFW), which was used as stock solution for the preparation of 50 and $25 \mathrm{mg} \mathrm{ml}^{-1}$ PFW solutions. When not in use, stock solutions were kept at $-20^{\circ} \mathrm{C}$. After extraction, leaves (or shoot tops) were dried at $60^{\circ} \mathrm{C}$ in an aerated oven and weighed to the nearest milligram, thus allowing concentrations to be expressed as plant dry weight volume ${ }^{-1}$ (PDW) after adding the dry weight of extracted material. Finally, for each donor species, four $2 \mathrm{ml}$ aliquots of the highest PFW were dried at $60^{\circ} \mathrm{C}$ in an aerated oven and the dry residues weighed to the nearest $0.1 \mathrm{mg}$, thus allowing 
concentrations to be expressed as extract dry weight volume $^{-1}$ (EDW).

The $\mathrm{pH}$ and osmotic pressure $(\psi \pi)$ of the three concentrations of all extracts were determined with a $\mathrm{pH}$-meter Metrohm E-520 (Metrohm AGH, Switzerland) and a semimicro freezing-point osmometer Knauer type M (Knauer, Wissenschaftliche Geräte GmbH, Germany) respectively.

\section{Effects of pH and osmotic pressure}

The experiment followed a dose-response design and a rationale similar to that described elsewhere for a $3 \times 4$ arrangement of $\mathrm{pH}$ (intended at 3.0, 4.5 and 6.0) and $\psi \pi$ (intended at $0,25,50$ and $\left.100 \mathrm{mOsmol} \mathrm{kg}{ }^{-1}\right)^{7}$, except that a $4 \times 2$ arrangement of $\mathrm{pH}$ (intended at 4.0, 5.0, 6.0 and 8.5) and $\psi \pi$ (intended at 0 and $25 \mathrm{mOsmol} \mathrm{kg}{ }^{-1}$ ) was used. Solutions were prepared with $0.1 \mathrm{M} \mathrm{HCl}$ or $\mathrm{NaOH}$ and polyethylene glycol PEG-400 (Carbowax, Fisher Chemical, USA average molecular weight 380-420). pH and $\psi \pi$ values were ascertained with a $\mathrm{pH}$-meter and a semi-micro freezing-point osmometer as described above. Four replicated $10 \mathrm{~cm}$ glass petri dishes were fitted with Whatman No. 1 filter paper, sown with 25 lettuce seeds, and wetted with $5 \mathrm{ml}$ of the appropriate $\mathrm{pH}$ and $\psi \pi$ solution. Seeds were incubated under $20^{\circ} \mathrm{C}$ and $8 \mathrm{~h}$ photoperiod provided by seven fluorescent tubes (Philips TLD $18 \mathrm{~W} / 84)$, considered germinated if the radicle was at least as long as the greater dimension of the seed ${ }^{10}$, and regularly counted and discarded during seven days.

\section{Extract phytoactivity}

Two replicated $10 \mathrm{~cm}$ glass petri dishes per donor species and concentration were fitted with Whatman No. 1 filter paper, sown with 50 lettuce seeds and wetted with $5 \mathrm{ml}$ of the appropriate extract. Controls were prepared similarly with distilled water adjusted with $0.2 \mathrm{M} \mathrm{HCl}$ to $\mathrm{pH} 5.3$. Seeds were incubated and considered germinated as described above. Germinated seeds were regularly counted and discarded during 14 days or less.

\section{Statistical analyses}

Linear regression analyses, Pearson's correlation coefficient analyses and ANOVA were done with Statgraphics 4.2 (STSC, Inc., Rockville, MD, USA), all other statistics with Excel®2010 (Microsoft Corporation, USA). Coefficients of determination $\left(R^{2}\right)$ of regressions with replication are presented as the proportion of maximum $R^{2}$ value possible ${ }^{11}$ and data as mean \pm SE.

The equation fitted previously ${ }^{7}$ to the relationship between $\mathrm{pH}$ and $\psi \pi$ and germination was used to generate expected values of germination using $\mathrm{pH}$ and $\psi \pi$ values of this experiment. Assessment of the adequacy of equa- tion was done using two-tailed Student's $t$ test for paired comparisons $^{12}$.

Given the result of the test we decided to fit a new equation pooling together data for which the equation had been originally fitted with data from this experiment, datasets A and B respectively (Supplementary Figure 1). As done before ${ }^{7}$, the relationship between jackknifed values ${ }^{13}$ of germination, and $\mathrm{pH}$ and $\psi \pi$ was investigated by stepwise least squares regression with replication and an experiment-wise error rate for coefficients of 0.01 calculated by Dunn-Šidák method ${ }^{14}$. Polynomials were used, and candidate models included up to the third power of $\mathrm{pH}$ or $\psi \pi$ and all interactions between them. Adequacy of the new equation was assessed as described above.

In germination bioassays, observed data ( $\left.Y_{\text {obs }}\right)$ were transformed to observed effects $\left(Y_{\mathrm{OE}}\right)$ as

$$
Y_{\mathrm{OE}}=\left(Y_{\mathrm{obs}}-\bar{Y}_{\mathrm{C}}\right) / \bar{Y}_{\mathrm{C}}
$$

where $\bar{Y}_{\mathrm{C}}$ is the observed mean of control. Thus, the control was normed so that the mean of its effects was zero. Positive values of $Y_{\mathrm{OE}}$ corresponded to values of observed germination higher than the control (stimulation), negative values to observed values lower than the control (inhibition). Values of germination to be expected from the combined effects of $\mathrm{pH}$ and $\psi \pi$ alone, regardless of the chemical composition of extracts, were calculated from eq. (2) below.

Expected values were transformed to expected effects $\left(Y_{\mathrm{EE}}\right)$ using eq. (1). Finally, effects corrected $\left(Y_{\mathrm{CE}}\right)$ for $\mathrm{pH}$ and $\psi \pi$ were determined by subtracting expected effects from observed effects $\left(Y_{\mathrm{CE}}=Y_{\mathrm{OE}}-Y_{\mathrm{EE}}\right)$. Corrected effects of all treatments were compared with those of control by two-tailed Student's $t$ test for unpaired comparisons after checking for homoscedasticity using the two-tailed $F$ distribution, always using a significance level of $P=0.05$.

Species for which statistically significant corrected effects of extracts were found were further analysed and the relationship between corrected effects and concentrations (PFW, PDW or EDW normed so that the highest concentration is unity) was studied by stepwise least squares regression with replication and an experiment-wise error rate for coefficients of 0.05 calculated by Dunn-Šidák method $^{14}$. Polynomials were used as candidate models, including up to the third power of normed concentrations and were forced through the origin because corrected effects for controls $\left(\mathrm{PFW}=\mathrm{PDW}=\mathrm{EDW}=0 \mathrm{mg} \mathrm{ml}^{-1}\right.$ ) are necessarily zero.

\section{Results}

\section{Effects of $\mathrm{pH}$ and osmotic pressure}

In some cases the intended values of $\mathrm{pH}$ or $\psi \pi$ in dataset B were not exactly matched (Supplementary Table 2). 
Nevertheless, because the overall design of the experiment is dose-response, the small differences observed do not prevent their use.

Significant differences were found between observed and predicted values of germination for all data $\left(t_{31}=\right.$ $3.416, P=0.002$ ) when the equation previously fitted to dataset $\mathrm{A}^{7}$ was used on dataset $\mathrm{B}$. Differences were essentially due to new combinations of $\mathrm{pH}$ and $\psi \pi$ values outside dataset A $\left(t_{15}=2.992, P=0.009\right)$ while for combinations common to datasets $\mathrm{A}$ and $\mathrm{B}$, no significant differences were found $\left(t_{15}=1.824, P=0.088\right)$. Ordering observed germination data of dataset $\mathrm{B}$ by the magnitude
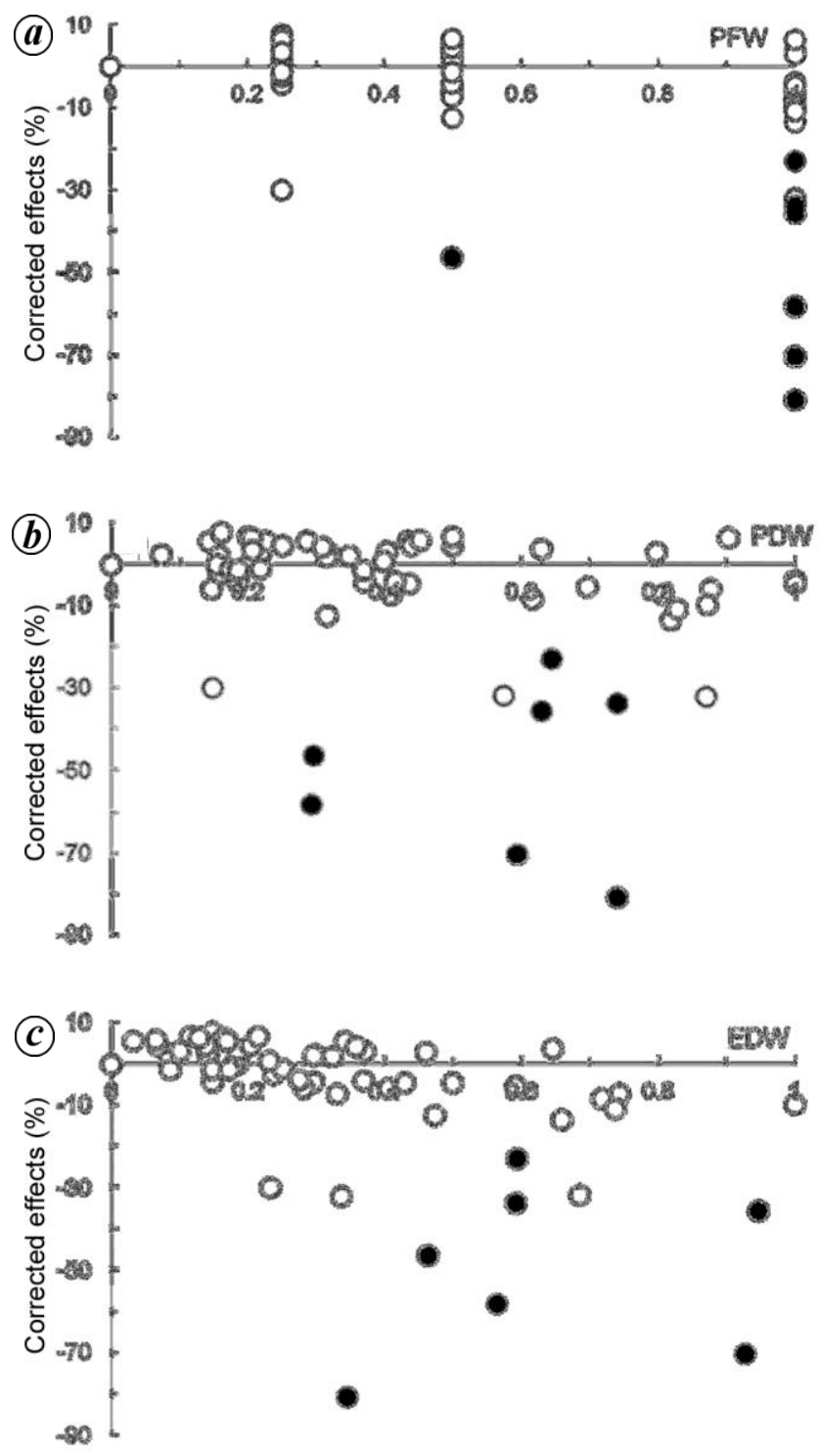

Figure 1. Relationship between effects of extracts corrected for $\mathrm{pH}$ and osmotic pressure on germination of Lactuca sativa cv. 'Rainha de Maio'. Extract concentrations are expressed as (a) plant fresh weight volume $^{-1}(\mathrm{PFW}),(\boldsymbol{b})$ plant dry weight volume ${ }^{-1}$ (PDW), and (c) extract dry weight volume ${ }^{-1}$ (EDW). All concentrations were normed so that the highest value was unity. Open symbols indicate no significant differences in relation to control and filled symbols show that effects are significantly different from control at $P=0.05$. of errors (observed minus predicted, regardless of sign) and sequentially removing errors starting with the largest,

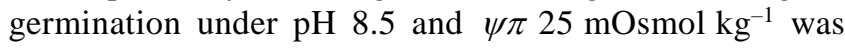
clearly the main cause of extrapolation failure $\left(t_{12}=\right.$ $1.678, P=0.121$ when the four larger errors, all from that combination, were removed).

Therefore we set out to fit a new equation pooling together data of datasets A and B. The equation fitted for the expected values of germination $\left(G_{\exp }\right)$ of lettuce was significant for all coefficients $(P<0.0002)$, lack of fit was significant $\left(F_{11,49}=5.076, P=3.051 \times 10^{-5}\right)$ and $R^{2}=0.654$. The new equation is

$$
\begin{aligned}
& G_{\exp }=95.52307-5.62467 \times 10^{-4} \psi \pi^{3}+1.60676 \\
& \times 10^{-4} \mathrm{pH} \psi \pi^{3}-1.86981 \times 10^{-6} \mathrm{pH}^{3} \psi \pi^{3} .
\end{aligned}
$$

The term in $\psi \pi$ alone accounts for $49.3 \%$ of the variation of germination explained by the equation, the two terms in $\mathrm{pH}$ and $\psi \pi$ for $50.7 \%$. No significant differences were found between observed and expected values for pooled data of datasets $\mathrm{A}$ and $\mathrm{B}\left(t_{63} \approx 0, P \approx 1\right)$, neither for dataset A alone $\left(t_{31}=1.692, P=0.101\right)$ nor for dataset $\mathrm{B}$ alone $\left(t_{31}=1.568, P=0.127\right)$.

\section{Extract concentration}

Concentrations of undiluted stock solutions $\left(100.0 \mathrm{mg} \mathrm{ml}^{-1}\right.$, PFW) expressed as plant dry weight volume ${ }^{-1}$ (PDW) had a coefficient of variation $(\mathrm{CV})$ of $22.5 \%$ ranging from $16.3 \mathrm{mg} \mathrm{ml}^{-1}$ in Foeniculum vulgare, indicating that more than $80 \%$ of its fresh weight was water, to $55.8 \mathrm{mg} \mathrm{ml}^{-1}$ in Quercus coccifera and Quercus ilex, both Fagaceae, indicating that less than half of their fresh weight was water (Supplementary Table 1). Extract concentration expressed as EDW had a larger coefficient of variation $(\mathrm{CV}=39.0 \%)$ ranging from $1.4 \mathrm{mg} \mathrm{ml}^{-1}$ in Quercus suber, indicating that less than $3 \%$ of biomass of intact leaves could be extracted by water, to $11 \mathrm{mg} \mathrm{ml}^{-1}$ in Phyllirea angustifolia (Supplementary Table 1). However, in a number of species the fraction of biomass of intact leaves (or shoot tops) that could be extracted by water was greater than that in $P$. angustifolia, the maximum being attained in $F$. vulgare in which almost $40 \%$ of biomass was extracted by water.

There was a clear trend of an inverse relationship between PDW and EDW, both expressed as percentage of PFW (Supplementary Figure $2 a$ ), but Pearson's correlation coefficient between them was not significant $\left(r_{18}=\right.$ $-0.405, P=0.077)$. However, when the data were reanalysed without $F$. vulgare, a significant negative correlation coefficient emerged $\left(r_{17}=-0.546, P=0.016\right)$. Using the ratio EDW/PDW instead of EDW/PFW (Supplementary Figure $2 b$ ), a highly significant negative correlation was observed even with $F$. vulgare present $\left(r_{18}=-0.845\right.$, 
$P<10^{-4}$ compared with $r_{17}=-0.773, P=10^{-4}$ without F. vulgare).

\section{Extract phytoactivity}

Germination ranged between $17.6 \% \pm 2.0 \%$ (C. villosa, higher concentration) and $98.0 \% \pm 0 \%$ (Cistus monspeliensis, lower concentration). Germination of control was $91.0 \% \pm 3.0 \%$. Effects ranged between $-80.6 \% \pm$ $2.2 \%$ and $7.7 \% \pm 0 \%$. Positive effects were found in $47 \%$ of bioassays, including all concentrations of Arbutus
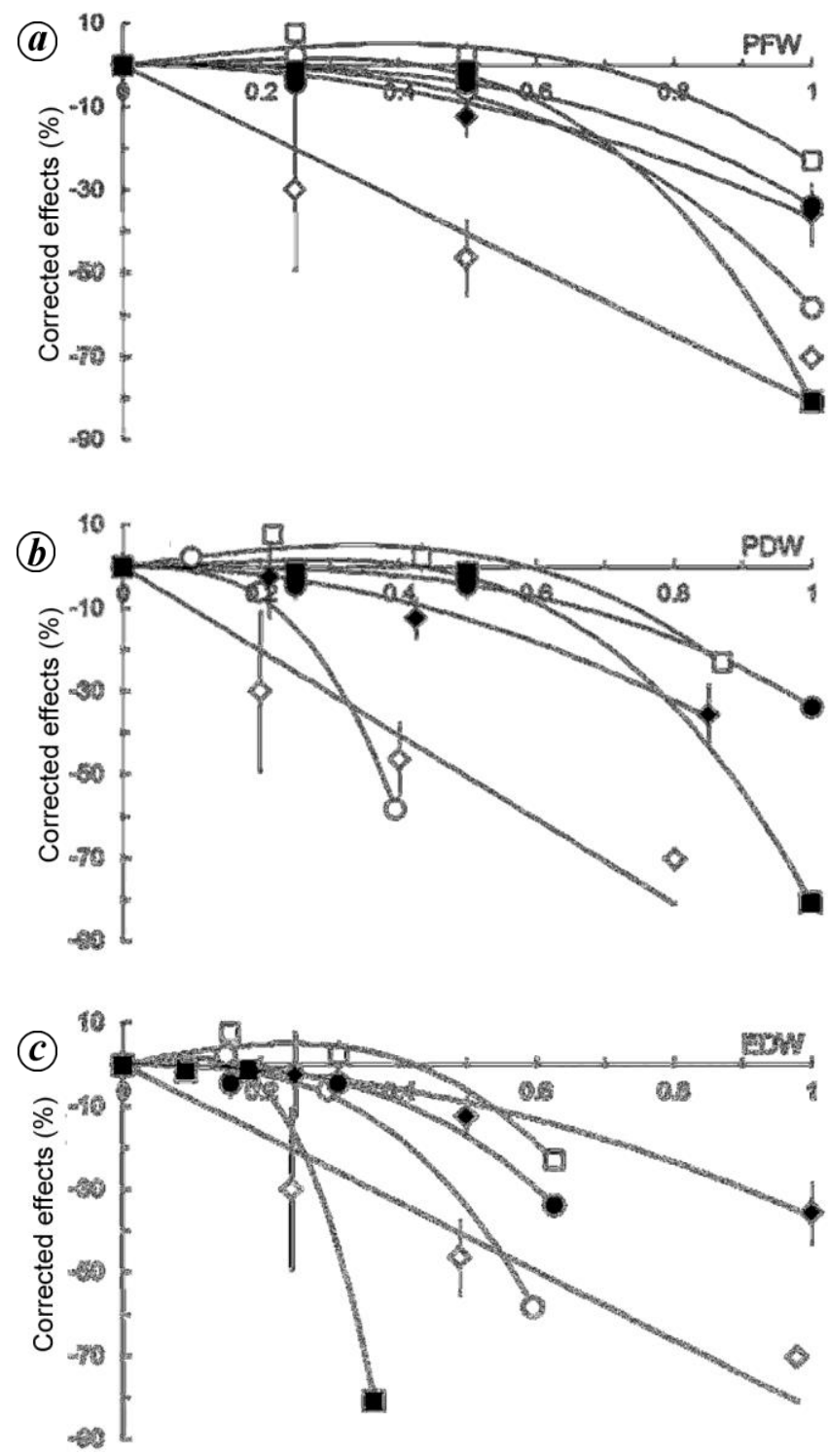

Figure 2. Expected and observed effects of extracts corrected for $\mathrm{pH}$ and osmotic pressure on germination of L. sativa cv. 'Rainha de Maio' (means \pm SE). Extract concentrations are expressed as (a) PFW, (b) PDW and (c) EDW. Concentrations were normed so that the highest value was unity. Open circles, Foeniculum vulgare; filled circles, Cistus ladanifer; open squares, Cistus monspeliensis; filled squares, Calicotome villosa; open diamonds, Lavandula stoechas and filled diamonds, Daphne gnidium. unedo and $Q$. suber, while negative effects were found in $53 \%$ of bioassays, including all concentrations of Cistus ladanifer, C. villosa, Lavandula stoechas, P. angustifolia and Daphne gnidium.

After being corrected, $\mathrm{pH}$ and $\psi \pi$ effects ranged between $-80.7 \% \pm 2.2 \%$ (C. villosa, higher concentration) and $7.7 \% \pm 0 \%$ (C. monspeliensis, lower concentration). Positive corrected effects were found in $44 \%$ of bioassays, including all concentrations of A. unedo, $Q$. suber and Cistus crispus, while negative corrected effects were found in $56 \%$ of bioassays, including all concentrations of the five species found in uncorrected effects.

Significant differences between corrected effects of extracts and control were found in the intermediate concentration of L. stoechas $\left(t_{2}=4.856, P=0.040\right)$ and in the higher concentrations of $F$. vulgare $\left(t_{2}=15.435\right.$, $P=0.004), C$. ladanifer $\left(t_{2}=9.236, P=0.012\right), C$. monspeliensis $\left(t_{2}=6.915, P=0.020\right), C$. villosa $\left(t_{2}=20.502\right.$, $P=0.002)$, L. stoechas $\left(t_{2}=12.315, P=0.007\right)$, and $D$. gnidium $\left(t_{2}=4.432, P=0.047\right)$.

When corrected effects were plotted against PFW (Figure $1 a$ ), there was a clear increase in the variability of responses with concentration, with almost all significant differences at the higher end of the range of concentrations. Conversely, when corrected effects were plotted against PDW (Figure $1 b$ ), the larger variability of responses and significant differences were located mostly in the middle of the range of concentrations, with the lower and higher ends showing less variability and no significant differences. Finally, when corrected effects were plotted against EDW (Figure $1 c$ ), the larger variability of responses and significant differences were located mostly in the upper half of the range of concentrations.

Regression equations could always be fitted to the relationship between corrected effects on germination of lettuce and concentration of extracts of the six species found to significantly affect germination, with coefficients of determination always greater than 0.966 (Supplementary Table 3). Relationships were always curvilinear, except in L. stoechas for which a straight line was found (Figure 2).

\section{Discussion}

\section{Effects of $\mathrm{pH}$ and osmotic pressure}

The possible contribution of $\mathrm{pH}$ and $\psi \pi$ to the effects of allelochemicals on germination has long been recognized but only rarely accounted for ${ }^{15,16}$, being assumed without evidences that $\mathrm{pH}$ and $\psi \pi$ act independently on seed germination.

The equation that was previously fitted to predict the response of germination of lettuce cv. 'Rainha de Maio' ${ }^{7}$ was based on a range of $\mathrm{pH}$ and $\psi \pi$ values that only 
partly coincided with the values measured in this study. That equation clearly had good interpolation properties but failed when used for extrapolation, especially for

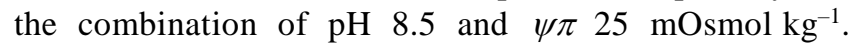
Therefore, its use outside the range for which it was originally fitted should be avoided. Conversely eq. (2) is clearly an adequate predictor of the combined effects of $\mathrm{pH}$ and $\psi \pi$ measured in extracts bioassayed in this experiment.

\section{Extract concentration}

Given the experimental design adopted, the concentration of all stock solutions expressed as PFW was necessarily the same. Naturally a completely different picture emerges when extracts concentration are expressed as PDW or EDW, with the variation in concentration extending by almost one order of magnitude in the latter.

Also, there is a clear inverse trend between PDW and EDW, stronger when the ratio EDW/PDW is used instead of EDW/PFW. This implies that as the amount of water in leaves (or shoot tops) decreases and consequently as PDW increases, there is a decrease in the amount of leaf or shoot top materials extractable by water in a gradient of diminishing water extractability from $F$. vulgare to the highly sclerophyllous Quercus.

\section{Extract phytoactivity}

Most parts of the extracts tested were ineffective, with less than one-third of species able to reduce germination of lettuce, a species known to be highly sensitive to exogenous phytochemicals ${ }^{5}$. This prevalence of ineffectiveness is somehow surprising because phytoactivity was reported in some of those species, namely Rosmarinus officinalis $^{17}$ and E. globulus $^{18}$, while the known phytochemical composition of others would make them strong candidates to affect germination, namely Cistus salviifolius $^{19}$, A. unedo ${ }^{20}$ or Myrtus communis ${ }^{21}$.

Chaparral shrubs and trees as those tested here produce high amounts of terpenoids ${ }^{22}$ known to possess a large spectrum of biological activities, notably phytoactivity and allelopathy ${ }^{23}$, their production increasing strongly, at least in isoprene and monoterpenes, as temperature rises $^{24}$. Therefore, explanation for the small number of phytoactive species found might be that the collection of materials for extraction was done in mid-winter, the rainy and colder season, while in the above-mentioned studies collection of plant materials was done in dry, hotter periods, when higher amounts of allelochemicals were probably present.

Conversely, to our knowledge there are no previous reports of allelochemicals phytoactivity for three of the six species effective on germination of lettuce, namely C. monspeliensis, C. villosa and D. gnidium.
When effective, significant inhibition of germination of lettuce after correction for $\mathrm{pH}$ and osmotic pressure extended from moderate to very intense, ranging from $-23 \%$ to $-81 \%$.

Ranking species by corrected effects, the least effective was $C$. monspeliensis and the most effective was $L$. stoechas followed by $C$. villosa and $F$. vulgare when extract concentration was expressed as PFW.

Ranking by PDW, the least effective was either D. gnidium or $C$. monspeliensis and the most effective was clearly $F$. vulgare because even if corrected effects were slightly less intense than those by L. stoechas and C. villosa, they resulted from a much lesser concentration in terms of plant dry weight.

Finally, ranking by EDW the least effective was again D. gnidium and the most effective was C. villosa, because not only its corrected effects were the largest but also because they were obtained from a much smaller amount of extracted allelochemicals.

Therefore, the way concentration of extracts is expressed has important consequences in ranking species by their effectiveness. Considering only the most effective species, expressing concentration by the usual plant fresh weight or plant dry weight, L. stoechas or F. vulgare respectively, two species known for their phytoactivity, top the list. Conversely, expressing concentration in terms of extract dry weight, the pioneer, spiny but digestible legume $C$. villosa $a^{25,26}$, known to produce a number of alkaloids, flavones, isoflavones, and pheno$\operatorname{lics}^{27-29}$ is undoubtedly the most effective species. This is noticeable because shoot tops instead of leaves had to be extracted, while a similar thorny legume, U. parviflorus, in which shoot tops had also to be extracted, had approximately the same dry/fresh weight ratio and twice the amount of extract dry weight, but was clearly ineffective.

Determining the weight of extracts is time-consuming and labour-intensive in relation to just weighing fresh plant parts or dry plant parts. However, it is clearly the most appropriate way to express extract concentration because it is the extracted materials alone and, not the extracted and non-extracted materials (as in PDW), or the latter and water (as in PFW) that are actually being assayed. Given the differences associated with the way concentration is expressed, determining extract weight is worth the additional effort, especially when implicit or explicit comparisons between sources of allelochemicals are intended.

1. Molisch, H., Der Einfluß Einer Pflanze auf die Andere. Allelopathie, Gustav Fischer, Jena, 1937.

2. Weidenhamer, J. D., Morton, T. C. and Romeo. J. T., Solution volume and seed number: often overlooked factors in allelopathic bioassays. J. Chem. Ecol., 1987, 13, 1481-1491.

3. Sinkkonen, A., Modelling the effect of autotoxicity on densitydependent phytotoxicity. J. Theor. Biol., 2007, 244, 218-227.

4. Pellisier, F., Improved germination bioassays for allelopathy research. Acta Physiol. Plant., 2013, 35, 23-30. 
5. Macías, F. A., Castellano, D. and Molinillo, J. M. G., Search for a standard phytotoxic bioassay for allelochemicals. Selection of standard target species. J. Agric. Food Chem., 2000, 48, 25122521.

6. Aslani, F. et al., Variation in the phytotoxic activity of Tinospora tuberculata extracts as influenced by solvent type and chemical profile. Curr. Sci., 2016, 110, 228-234.

7. Dias, A. S., Pereira, I. P. and Dias, L. S., Investigating and modeling the combined effects of $\mathrm{pH}$ and osmotic pressure on seed germination for use in phytoactivity and allelopathic research. Plant Biosyst., 2016, 151, 657-664.

8. An, M., Johnson, I. R. and Lovett, J. V., Mathematical modeling of allelopathy: biological response to allelochemicals and its interpretation. J. Chem. Ecol., 1993, 10, 2379-2388.

9. Weidenhamer, J. D., Hartnett, D. C. and Romeo, J. T., Densitydependent phytotoxicity: distinguishing resource competition and allelopathic interference in plants. J. Appl. Ecol., 1989, 26, 613624.

10. Rietveld, W. J., Phytotoxic grass residues reduce germination and initial root growth of ponderosa pine. USDA Forestry Service Research Paper, RM-153. Fort Collins, 1975.

11. Draper, N. R. and Smith, H., Applied Regression Analysis, 3rd edn, Wiley, New York, USA, 1998.

12. Robinson, A. P. and Froese, R. E., Model validation using equivalence tests. Ecol. Model., 2004, 176, 349-358.

13. Efron, B., The Jackknife, the Bootstrap and other Resampling Plans, Society for Industrial and Applied Mathematics, Philadelphia, USA, 1982.

14. Ury, H. K., A comparison of four procedures for multiple comparisons among means (pairwise contrasts) for arbitrary sample sizes. Technometrics, 1976, 18, 89-97.

15. Evenari, M., Germination inhibitors. Bot. Rev., 1949, 15, 153 194.

16. Chou, C. H. and Young, C. C., Effects of osmotic concentration and $\mathrm{pH}$ on plant growth. Taiwania, 1974, 19, 157-165.

17. Angelini, L. G., Carpanese, G., Cioni, P. L., Morelli, I. Macchia, M. and Flamini, G., Essential oils from Mediterranean Lamiaceae as weed germination inhibitors. J. Agric. Food Chem., 2003, 51, 6158-6164.

18. Bagavathy, S. and Xavier, G. S. A., Effects of aqueous extract of Eucalyptus globulus on germination and seedling growth of sorghum. Allelopath. J., 2007, 20, 395-401.
19. Demetzos, C., Angelopoulou, D. and Perdetzoglou, D., A comparative study of the essential oils of Cistus salviifolius in several populations of Crete (Greece). Biochem. Syst. Ecol., 2002, 30, 651-665.

20. Andrade, D., Gil, C., Breitenfeld, L., Domingues, F. and Duarte, A. P., Bioactive extracts from Cistus ladanifer and Arbutus unedo. Ind. Crop Prod., 2009, 30, 165-167.

21. Asllani, U., Chemical composition of Albanian myrtle oil (Myrtus communis L.). J. Essent. Oil Res., 2000, 12, 140-142.

22. Lebreton, P. and Gallet, C., Les communautés végétales sont biochimiquement organisées. Acta Bot. Gallica, 2007, 154, 573-595.

23. Iason, G. R. et al., Plant secondary metabolite polymorphisms and the extended chemical phenotype. In The Ecology of Plant Secondary Metabolites. From Genes to Global Processes (eds Iason, G. R., Dicke, M. and Hartley, S. E.), Cambridge University Press, Cambridge, UK, 2012, pp. 247-268.

24. Bagnoli, F., Fineschi, S. and Loreto, F., Volatile isoprenoids and abiotic stress. In The Ecology of Plant Secondary Metabolites. From Genes to Global Processes (eds. Iason, G. R., Dicke, M. and Hartley, S. E.), Cambridge University Press, Cambridge, UK, 2012, pp. 101-119.

25. Ammar, H., López, S. and González, J. S., Assessment of the digestibility of some Mediterranean shrubs by in vitro techniques. Anim. Feed Sci. Technol., 2005, 119, 323-331.

26. Arroyo, J., Aparicio, A., Albaladejo, R. G., Muñoz, J. and Braza, R., Genetic structure and population differentiation of the Mediterranean pioneer spiny broom Calicotome villosa across the Strait of Gibraltar. Biol. J. Linn. Soc., 2008, 93, 39-51.

27. Harborne, J. B., Chemosystematics of the Leguminosae. Flavonoid and isoflavonoid patterns in the tribe Genisteae. Phytochemistry, 1969, 8, 1449-1456.

28. Dessí, M. A. et al., Antioxidant activity of extracts from plants growing in Sardinia. Phytother. Res., 2001, 15, 511-518.

29. Pistelli, L., Fiumi, C., Morelli, I. and Giachi, I., Flavonoids from Calicotome villosa. Fitoterapia, 2003, 74, 417-419.

ACKNOWLEDGEMENT. We thank Maria Gertrudes Grenho for technical assistance.

Received 21 March 2017; revised accepted 24 May 2018

doi: $10.18520 / \mathrm{cs} / \mathrm{v} 115 / \mathrm{i} 5 / 904-909$ 


\section{Supplementary Information}

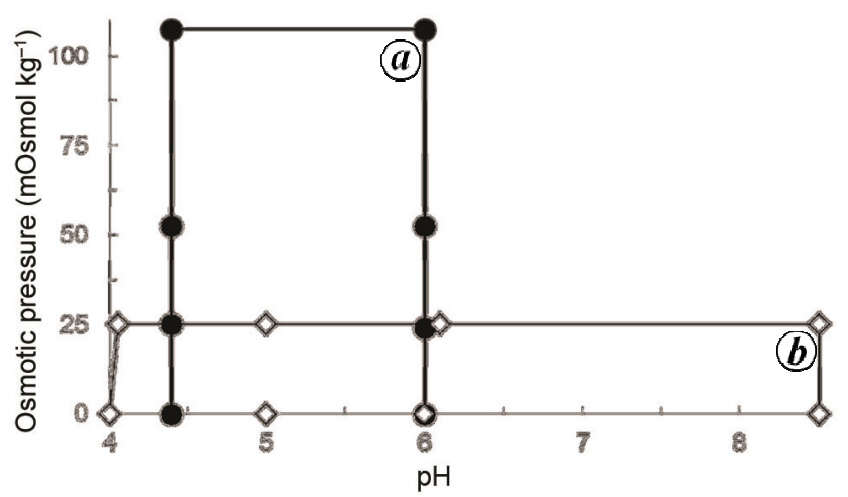

Figure 1 Schematics of range of $\mathrm{pH}$ and osmotic pressure-values $(\psi \pi)$ investigated to fit calibration surfaces for Lactuca sativa cv. 'Rainha de Maio' seed germination. a, delimited by closed circles, used to fit calibration surface in Dias et al., Plant Biosyst., 2016, 151, 657-664; $\boldsymbol{b}$, delimited by open diamonds, the new combinations of $\mathrm{pH}-$ and $\psi \pi$-values found in extracts bioassayed in this work.
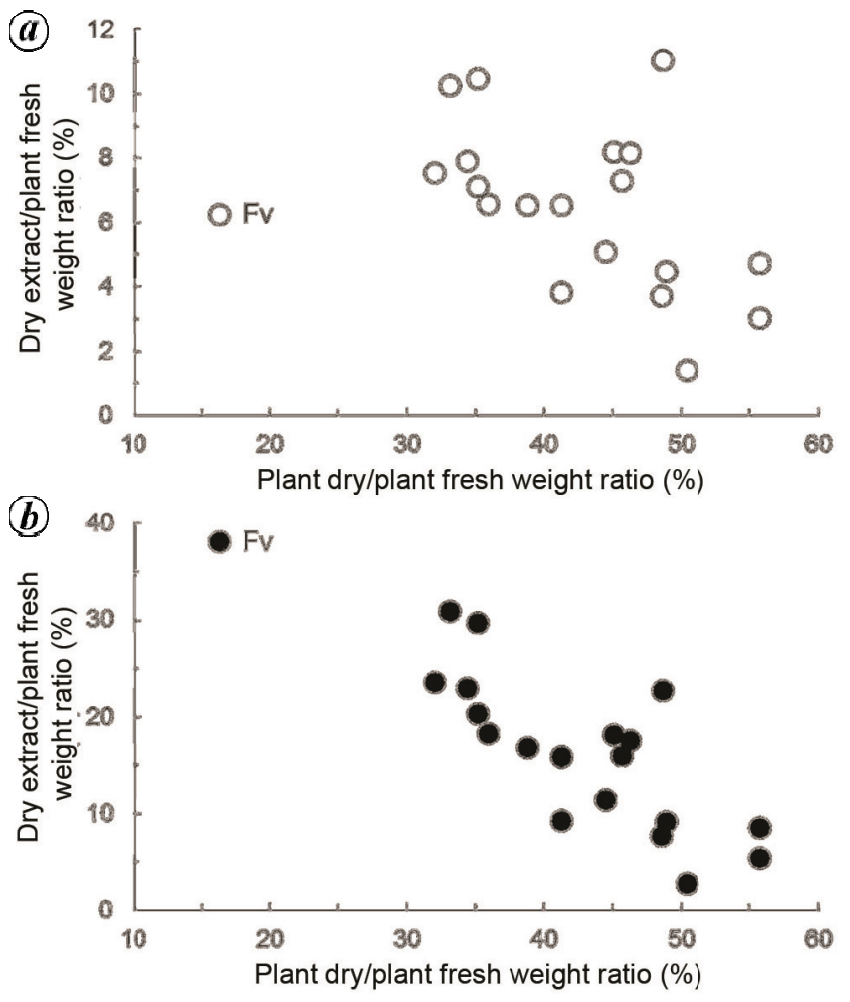

Figure 2. Plot of the relationship between the ratio plant dry weight/plant fresh weight of nineteen Mediterranean-type shrubs and trees and $(a)$ the ratio dry weight of extract/plant fresh weight (open circles), and (b) the ratio dry weight of extract/plant dry weight (closed circles). All ratios expressed as percentages. Fv indicates the location of Foeniculum vulgare. 
Table 1. Species and families tested for allelochemical activity of water extracts of intact leaves or shoot tops. Dry matter concentration and dry extract concentration correspond to the larger concentration of fresh material $\left(100 \mathrm{mg} \mathrm{ml}^{-1}\right)$

\begin{tabular}{|c|c|c|c|c|}
\hline Species & Family & Habit & $\begin{array}{l}\text { Dry matter } \\
\text { concentration } \\
\left(\mathrm{mg} \cdot \mathrm{ml}^{-1}\right)\end{array}$ & $\begin{array}{c}\text { Dry extract } \\
\text { concentration } \\
\left(\mathrm{mg} \mathrm{ml}^{-1}\right)\end{array}$ \\
\hline Pistacia lentiscus L. & Anacardiaceae & Tree or shrub & 48.9 & 4.5 \\
\hline Foeniculum vulgare Mill. & Apiaceae & Shrub & 16.3 & 6.2 \\
\hline Cistus crispus L. & Cistaceae & Shrub & 35.1 & 7.1 \\
\hline Cistus ladanifer $\mathrm{L}$. & Cistaceae & Shrub & 41.3 & 6.5 \\
\hline Cistus monspeliensis L. & Cistaceae & Shrub & 35.9 & 6.6 \\
\hline Cistus salviifolius L. & Cistaceae & Shrub & 32.0 & 7.6 \\
\hline Arbutus unedo L. & Ericaceae & Shrub or tree & 44.5 & 5.1 \\
\hline Calicotome villosa (Poir.) & Link Fabaceae & Shrub & 41.2 & 3.8 \\
\hline Ulex parviflorus Pourr. & Fabaceae & Shrub & 45.7 & 7.3 \\
\hline Quercus coccifera $\mathrm{L}$. & Fagaceae & Shrub & 55.8 & 3.0 \\
\hline Quercus ilex L. & Fagaceae & Tree & 55.8 & 4.7 \\
\hline Quercus suber L. & Fagaceae & Tree & 50.4 & 1.4 \\
\hline Lavandula stoechas $\mathrm{L}$. & Lamiaceae & Shrub & 33.1 & 10.2 \\
\hline Rosmarinus officinalis L. & Lamiaceae & Shrub & 34.4 & 7.9 \\
\hline \multirow{2}{*}{ Eucalyptus globules Labill. } & Myrtaceae & Tree & 38.8 & 6.5 \\
\hline & & & 48.5 & 3.7 \\
\hline Myrtus communis $\mathrm{L}$. & Myrtaceae & Shrub & 45.0 & 8.2 \\
\hline Olea europaea $\mathrm{L}$. & Oleaceae & Tree & 46.2 & 8.1 \\
\hline Phillyrea angustifolia $\mathrm{L}$. & Oleaceae & Shrub & 48.6 & 11.0 \\
\hline Daphne gnidium L. & Thymelaeaceae & Shrub & 35.1 & 10.4 \\
\hline
\end{tabular}

Names and authorities according to The Plant List 2013, Version 1.1 released September 2013, http://www.theplantlist.org (accessed 4 May 2015). In Eucalyptus globulus the first line refers to young leaves, the second to mature leaves.

Table 2. $\mathrm{pH}$ and osmotic pressure $(\psi \pi)$ of treatments, and values (means $\pm \mathrm{SE}$ ) of seed germination of Lactuca sativa cv. 'Rainha de Maio'. All means with $n=4$

\begin{tabular}{|c|c|c|}
\hline $\mathrm{pH}$ & $\psi \pi\left(\mathrm{mOsmol} \mathrm{kg}{ }^{-1}\right)$ & Germination (\%) \\
\hline 4.0 & 0.0 & $96.0 \pm 1.6$ \\
\hline 4.05 & 25.0 & $95.0 \pm 1.9$ \\
\hline \multirow[t]{2}{*}{5.0} & 0.0 & $90.0 \pm 3.5$ \\
\hline & 25.0 & $93.0 \pm 1.0$ \\
\hline 6.0 & 0.0 & $98.0 \pm 1.2$ \\
\hline 6.1 & 25.0 & $97.0 \pm 1.0$ \\
\hline \multirow[t]{2}{*}{8.5} & 0.0 & $94.0 \pm 3.5$ \\
\hline & 25.0 & $90.0 \pm 1.2$ \\
\hline
\end{tabular}


Table 3. Regression coefficients for equations fitted to the relationship between effects of extracts corrected for pH and osmotic pressure on percentage of seed germination of Lactuca sativa cv. 'Rainha de Maio' and extracts concentration expressed as plant fresh weight·volume ${ }^{-1}$ (PFW), plant dry weight $\cdot$ volume ${ }^{-1}(\mathrm{PDW})$, and extract dry weight $\cdot$ volume $^{-1}(\mathrm{EDW})$

\begin{tabular}{|c|c|c|c|c|c|c|c|}
\hline & & $\begin{array}{c}\text { Foeniculum } \\
\text { vulgare }\end{array}$ & $\begin{array}{c}\text { Cistus } \\
\text { ladanifer }\end{array}$ & $\begin{array}{c}\text { Cistus } \\
\text { monspeliensis }\end{array}$ & $\begin{array}{c}\text { Calicotome } \\
\text { villosa }\end{array}$ & $\begin{array}{c}\text { Lavandula } \\
\text { stoechas }\end{array}$ & $\begin{array}{l}\text { Daphne } \\
\text { gnidium }\end{array}$ \\
\hline \multirow[t]{2}{*}{ PFW } & $\mathrm{a}$ & - & - & 19.534 & - & -81.033 & - \\
\hline & $\mathrm{c}$ & -57.940 & -33.736 & -42.766 & -141.647 & - & - \\
\hline \multirow[t]{2}{*}{ PDW } & $\mathrm{a}$ & - & - & 22.467 & - & -101.095 & - \\
\hline & $\mathrm{b}$ & - & - & - & 61.099 & - & -50.433 \\
\hline \multirow[t]{3}{*}{ EDW } & $\mathrm{a}$ & - & - & 31.166 & - & -82.715 & - \\
\hline & $\mathrm{b}$ & - & - & - & 485.254 & - & -36.555 \\
\hline & $\mathrm{c}$ & -274.101 & -137.786 & -173.671 & -2916.941 & - & - \\
\hline$P_{\text {model }}$ & & $<10^{-4}$ & $<10^{-4}$ & 0.0002 & $<10^{-4}$ & 0.0004 & 0.0002 \\
\hline$P_{\text {coefficients }}$ & & $<10^{-4}$ & $<10^{-4}$ & $\leq 0.0004$ & $\leq 0.008$ & 0.0004 & 0.0002 \\
\hline$R^{2}$ & & 0.997 & 0.987 & 0.972 & 0.998 & 0.966 & 0.992 \\
\hline \multirow[t]{2}{*}{ LOF } & $F$ & 1.899 & 1.103 & 3.917 & 3.171 & 0.792 & 0.155 \\
\hline & $\mathrm{df}$ & 2,5 & 2,5 & 1,5 & 1,5 & 2,4 & 2,5 \\
\hline
\end{tabular}

All concentrations were normed so that the highest is unity. The general equation is $Y=a X+b X^{2}+c X^{3}$, with $Y$ being corrected effects, and $X$ being normed concentrations. Also shown are significance levels of fitted models, the larger significance level of coefficients, coefficients of determination $\left(R^{2}\right)$, and $F$-values, degrees of freedom $(d f)$ and significance levels of lack of fit tests (LOF). 